This item was submitted to Loughborough's Research Repository by the author.

Items in Figshare are protected by copyright, with all rights reserved, unless otherwise indicated.

\title{
Ideology: towards renewal of a critical concept
}

PLEASE CITE THE PUBLISHED VERSION

http://dx.doi.org/10.1177/0163443716671494

\section{PUBLISHER}

Sage (@) The Authors)

\section{VERSION}

VoR (Version of Record)

\section{PUBLISHER STATEMENT}

This work is made available according to the conditions of the Creative Commons Attribution-NonCommercialNoDerivatives 4.0 International (CC BY-NC-ND 4.0) licence. Full details of this licence are available at: https://creativecommons.org/licenses/by-nc-nd/4.0/

\section{LICENCE}

CC BY-NC-ND 4.0

\section{REPOSITORY RECORD}

Downey, John, and Jason Toynbee. 2019. "Ideology: Towards Renewal of a Critical Concept”. figshare. https://hdl.handle.net/2134/23095. 


\section{Ideology: towards renewal of a critical concept}

In Downey, Titley and Toynbee (2014) we issued a challenge to media studies. We argued that what is missing from contemporary media studies is a critical concept of ideology that guides academic analysis and political praxis. Our polemical intervention has met with some consternation but at least some partial agreement. We take encouragement from this, accepting the opportunity of replying to our critics and fellow-travelers. In doing so we will adopt a different register as our primary objective of sparking debate has been achieved and now there is a need for deliberation, openness, and recognition of uncertainty. We will, therefore, focus our response on where we believe that there can be productive debate about the coherence of the concept. To clear up one misunderstanding from the outset, we do not want a transposition of Hall's critique of Thatcherism to the present historical conjuncture (Phelan, 2016: 277). Our position is that we cannot resurrect previous notions of ideology as though they had no difficulties in a sort of 'ideology nostalgia' for when the concept was common in the field but that we need to engage in significant conceptual renewal drawing insights from work in a variety of disciplines and fields. This response is meant as merely a step in this process of moving on but one that we hope will find a resonance with the readers of this journal.

\section{Ideology: strategic and deceptive intent?}

Two adjectives commonly used to denote agents engaging in ideological ways of thinking are 'strategic' and 'deceptive'(Corner, 2016: 265). 'Strategic' we take to mean the intentional use of language with the aim of persuading another agent of the validity of a particular position. If we adopt this definition, however, it is difficult to associate ideology peculiarly with strategic intent as all forms of language use have perlocutionary intent (Austin, 1962). That ideology has a strategic intent is thus not a defining characteristic of ideology per se. Likewise with ‘deception’ we consider that agents engaging in ideological ways of thinking may be being deceptive (i.e. they might not believe their reasons themselves) but equally they might believe them to the letter. Not only is it difficult to discern ideological intent 
without further evidence but also whether the intent is deceptive is actually irrelevant to the claim that a way of thinking is ideological or not. It has to do with the internal form of the argument or narrative not with the intent, deceptive or otherwise, of the agent. One of the suggestions for the renewal of ideology critique, therefore, is that we disassociate it from notions of strategic and deceptive intent.

\section{Does losing the concept of ideology actually matter for critique?}

Both Corner and Phelan in their responses to our essay argue that there is much critical work going on that we have either missed or does not use the concept of ideology with the implication being that the concept is at the very least not an essential part of the critical vocabulary of an engaged media studies scholar. Phelan (2016: 278) argues that a lot of ideology critique is going on that simply does not call itself ideology critique, which prompts the question: why not? John Corner (2016:269) notes how the retreat from the use of ideology has not coincided with a retreat from an analysis of power with the journal Media, Culture and Society being in the vanguard of critical work about power. We would accept this. Indeed, it makes the journal the most obviously fertile ground precisely for this debate - that there is something missing in contemporary critique. Phelan (2016: 275) argues that 'the ubiquity of 'neoliberalism' as a critical keyword' testifies to the widespread interest in ideology critique though it does not identify itself as such. While we agree that the concept of neoliberalism is widely used in a pejorative sense across social science and humanities disciplines it is not always clear from where critique takes place. It is, of course, possible to be critical of neoliberalism from a neo-Keynesian social democratic position as well as from more radical democratic perspectives to mention just challenges to neoliberalism from the left. Many denunciations of neoliberalism from the left are also rather vague as to their own position. As Nicholas Gane (2012: 613) and others have pointed out, neoliberalism has become ‘a convenient bogeyman’. We tend very much to agree with Simon Dawes’ (2016: 285-7) analysis of the limitations of much 'critical' work on neoliberalism but our solution is not to turn towards Foucault but to argue for a repaired concept of ideology critique. 
In an earlier review essay Corner (2001) argued that we should ditch the concept of ideology while still attending to the questions that the concept engaged with (for example, the legitimation of inequality). We accept that this was Corner's intention and it finds admirable and sustained expression in his work. Our concern, however, is that if critique loses its foundations then why would we raise concerns about inequality in the first place and its (re)production through media and other cultural forms? The concept of ideology provides the platform from which analysis springs and we should not easily separate off the asking of questions from their ethical and theoretical underpinnings. This argument goes to the heart of critique. From where do we criticize and what makes this position reasonable as opposed to other conceptions? Without this ethical foundation, we think that we will slip into either 'critique light' or we will have drifted into work that is not critical at all. Renewing ideology critique involves, therefore, being explicit about its ethical foundations. If we cannot show you this then we do not give anyone a good reason to change how they work. Ideology critique is about not only showing how language is used to justify a state of affairs but that this state of affairs is wrong. Corner is right when he argues that some proponents of ideology critique have done much ritual denunciation of the latter and not much of the former, what might be termed 'analysis light'. Much contemporary critical work, however, leaves the ethical foundation of the critique itself implicit. We have some sympathy with this position. We want to say that something is wrong without quite being able to put our finger on why it is wrong. We think the problem is down to a narrowing of the intellectual inheritance of media studies and that if we look beyond the canon of the field more, then we can find resources useful to the project of the reconstruction of ideology critique.

\section{The reflexive turn in political philosophy}

Downey (2008) argues that there are intellectual resources available for the renewal of ideology critique that are largely overlooked by media scholars. Media studies’ engagement with the Frankfurt School seems to be restricted now either to Adorno and Horkheimer's classic culture industry essay or Habermas' early work on the public sphere. While it is evident that Media, Culture and Society as a 
journal is committed to the cause of critique, contributors have overlooked the work of third and now fourth generation Critical Theorists such as Axel Honneth and Rainer Forst. The work of Honneth and, in particular, Forst provide vital resources for the repair of ideology critique.

Forst's project is to make political philosophy take a reflexive turn. The central question in political philosophy is the justification of political rule. Forst makes the question contextual and reflexive by asking who poses this question and who has the authority to answer it. The idea of discursive justice as fundamental is embedded in the posing of the question of legitimacy and this provides 'at once (a) substantial and procedural foundation of a just society’ (2014: 3). Logically, claims to general and reciprocal validity can only be made good in a discursive context of generality and reciprocity. Claims to legitimacy presuppose the validity of a discursive context in which claims can be settled. This presupposed condition of reciprocity is Forst's key insight, which provides both the historical and a priori grounds for ideology critique making traditional oppositions between immanent and transcendental critique superfluous. Forst regards persons as active agents in need of justifications requiring reciprocity i.e. equality in terms of engaging in debate and in decision-making about matters affecting their lives. For Forst this reciprocity is the 'first requirement of justice'(2014: 5). This both implicit and ideal notion of reciprocity provides the reference or vantage point from which we engage in critique of practices and forms of thinking that stand in the way of creating egalitarian forms of life. It guides the questions we ask, the analysis we engage in. The definition of ideology critique becomes: an analysis of the (unjust) ways in which unrecriprocal or unequal relationships between persons are justified. According to Forst, to engage in an ideology critique is to undertake, following Honneth's expression, a pathology of reasons to ascertain how in specific times and places the unjustifiable is justified.

\section{Ideology: what's it like outside?}

Phelan (2016: 282) suggests that a way forward in thinking about ideology at the end of his contribution by bringing together the critical and descriptive meanings of ideology. However, there are logical 
problems with this. Although Phelan embraces the apparent contradiction as opening up 'a new, more imaginative horizon' he essentially ditches the critical conception of ideology in favour of a descriptive one. Ideology should be reconceptualised so that it is recognized that it always with us and not ‘something inherently malign' and that we should endeavor to find 'better forms of ideological attachment'(2016: 282). We do not see how this approach is consistent with earlier claims to critical intent as it appears to cede the meaning of ideology over entirely to the descriptive tradition. In the critical tradition the idea of a better or worse form of ideological attachment does not make much sense.

With the descriptive definition of ideology there is no outside of ideology - we all have some sort of ideological attachment. It is a macro-approach in that ideologies are thought to be very large belief systems that entirely structure experience (McCartney, 1976). Here there is some affinity with traditional critical conceptions of ideology (and which we would like to distance ourselves from), where there appears to be no outside or rather it is conveniently occupied by the proponents of ideology critique basking in their true consciousness (Corner, 2016: 267). Corner (2016:271) argues that Downey (2008) is advocating a macro-perspective. Certainly what we are arguing for is a universal ethical foundation that grounds ideology critique of unjust ways of thinking. This ethical foundation is valid across time, space and cultures. What we are not arguing for, however, is a position that assumes the existence of macro, monolithic belief systems and that agents are entirely ensnared within them.

To repeat, what counts in ideological analysis is the extent to which a given account, explanation or narrative justifies (unjust) unreciprocal or unequal relationships between persons. It follows that critique guided by universal ethical foundation should operate on an empirical, historical and case-by-case basis. When approached in this way it becomes clear that ideology can operate at a range of levels. But even at its most macro, as for instance in the proposition that the market is the only natural, efficient and fair way of provisioning, it may be ignored, rejected, or simply not get through to everyone. In short, considered as a speech act ideology is often infelicitous, and when it is most powerful in its effects it is never all 
powerful. This suggests that quite apart from a self-reflective practice called ideology critique there is a lay outside to ideology, a place where ideology is resisted, ignored or where it simply doesn't reach. Once again, (and without wishing to return to the school of Stuart Hall) we note that this position is quite venerable in media studies (Hall 1973).

\section{Foucault-phobes of the world unite?}

As we mentioned, we agree to a large extent with Dawes assessment of the limitations of much of the critical work on neoliberalism and think that this goes to strengthen our argument about the need for a repaired ideology critique. Dawes takes an alternative view and argues that the problem is actually caused by the hegemony of ideology critique (2016: 287). He argues that what is required is a move towards a more Foucauldian position but one that he sees as compatible with what we want to do if only we could recognise this and were not blinded by our Northern hemisphere Foucault-phobia. We do think that Dawes and Phelan have a point in taking us to task for our flippant and casual dismissal of Foucault. Foucault and Foucauldians offer important approaches, insights and concepts. As Dawes argues, the genealogical approach can help address historical change and complexity complementing, for example, a Marxisant approach. We certainly would not wish to dismiss a whole body of work and are very much tempted to adopt concepts, insights, approaches wherever we find them if we think that they help in the task of the reconstruction of ideology critique. That said, we argue that a such a critique is incompatible with some basic Foucauldian assumptions. We have already talked about the need for a universal ethical foundation (provided by Rainer Forst), from which we might ground ideology critique normatively. But there is also a need to think through certain epistemological dimensions. Bluntly put, Foucault’s 'flat' epistemology in which social being is collapsed into knowing via such formulations as power/knowledge cannot easily support ideology critique. Ideology critique presupposes a real social world which even while it is socially constructed also exists independently of any theories about it. The key point concerning ideology is then that it obscures aspects of that world, helping to reinforce inequality through 
techniques of normalisation. We argued above that ideology does not entail deceptive intent. But it certainly does involve bad knowledge in the sense of misleading knowledge, or getting reality wrong, whether or not that is the intention of the propagators of the ideology in question.

Critical realism helps justify this proposal by positing a realist ontology according to which the world exists, including intangible social structures and discourses as well as the material domain. However to know the world is difficult. Moreover, knowledge changes historically. What's called for then is an epistemological relativism, which recognises the fallible and changing nature of knowledge. However, in a third step critical realism argues for judgemental rationality. Albeit that knowledge is fallible and changeable, there are ways of adjudicating between different accounts, theories and so on according to their explanatory power (for an introduction to this schema see Collier, 1994).

The implications of critical realism for ideology critique are that we can indeed pose an 'outside' from which it is possible to gather evidence and make judgements about ideology in the real social world. But there is no possibility of certainty about such judgements, as is implied in the attribution of 'false consciousness' to a subject, or in those theories which have ideology as a total system, more or less coterminous with consciousness itself. Rather, we argue that ideology critique needs to take a more modest position, from which it is possible to 'call out' ideology, but only on the familiar basis in social science of empirical methodology.

\section{Is there a power deficiency in media studies?}

Corner in a very intelligent approach to whether the concept of ideology is useful or not, asks what is wrong with critical work that eschews the concept of ideology while employing the notion of power. If such work has limitations then it opens up some space for the reintroduction of ideology critique. There are, Corner contends, a number of limitations to do with a relative neglect of the affective dimension of news language that is only recently being addressed and with a limited range of sources excluding often 
drama and popular culture. We would heartily agree with Corner here. However, we think there is a much more fundamental problem with the way that the concept of power is used in media analysis. Our position is that we need a critical conception of ideology and a concept of power working together and that media studies needs to reconstruct both in a fundamental way.

The essential problem with the concept of power in media studies is that it is inflated to include almost everything and it is seen as a bad thing. Again media studies scholars may benefit from engaging with recent work on power in the field of political philosophy (see for instance Allen, Forst, Haugaard (2014)). As Corner argues the use of the concept of the ideology was displaced as least initially by discourse in an essentially Foucauldian move. In a quite different and much more Marxisant Bourdieu-inspired approach the concept of cultural power is employed instead of ideology but the 'worker concepts' (concepts that do the analytical heavy-lifting such as 'naturalisation') often remain the same. In a sense what had changed was the intellectual scaffolding. The problem with both approaches is that power becomes a catch-all concept and is clearly bad. The problem with applying power to language use is that the language use that we are primarily interested in operates through persuasion (encouraging another agent to see the world in a particular way) whereas economic and political power employs material resources as either sanctions or inducements in an attempt to get agents to behave in particular ways. They may be successful on a purely material level without persuading the people concerned about the legitimacy of what is going on. To collapse the analysis of persuasion into the analysis of power seems to us to be unhelpfully reductive, combining quite different types of things. What we need is an analysis of both together as, of course, the world is a complex mixture of persuasion, sanction, and inducement.

Much more fundamentally, however, we think the critical variant of media studies has a problem with power in that it is conceptualised as being intrinsically bad. To borrow Corner's approach, let us examine the situation from the opposite end. Let us pose the question: when is the exercise of power legitimate? We think that in media studies the answer would have to be 'never'. If we imagine a democratic society 
characterized by equality of opportunity of participation in debates and decision-making then the laws produced should generally be abided by unless they offend against the foundational principles of generality and reciprocity and so the exercise of power over citizens who decide not to abide by them is a legitimate exercise of power. There can, therefore, for us be legitimate and illegitimate forms of power. The concept of power itself, therefore, should be a neutral, not a normative, one. Power should not as be seen as necessarily illegitimate, which is how it tends to be viewed in critical media analysis. It is as if the pejorative concept of ideology has been replaced by a pejorative concept of power but without resolving the issues that led to the decline in the use of the concept of ideology. What should interest us is how the exercise of power is legitimated and whether it is, in fact, legitimate case-by-case. This places us firmly back, we believe, on the terrain of ideology critique.

\section{Legitimating Neoliberalism}

In the final section of his 1982 essay, Hall argues that broadcast media institutions, such as the BBC, despite their claim to impartiality not only reflect consensus (or dominant values) but also play a role in the production of consent. For Hall, the state is key to this because it is through the state that particular interests acquire their legitimacy which then become reflected and reproduced by media institutions:

Note that we have said 'the state', not particular parties or economic interests. The media, in dealing with contentious public or political issues, would be rightly held to be partisan if they systematically adopted the point of view of a particular political party or of a particular section of capitalist interests. It is only in so far as (a) these parties or interests have acquired legitimate ascendancy in the state, and (b) that ascendancy has been legitimately secured through the formal exercise of 'the will of the majority' that their strategies can be represented as coincident with the 'national interest' - and therefore form the legitimate basis or framework which the media can assume (1982: 83) 
A key difference between the historical conjuncture that informed the writing of Hall's essay (1982) and our particular historical conjuncture is that the role the state plays has been fundamentally altered. There has been a revolutionary inversion of the relations of legitimacy between capital and the state. The legitimacy of the state is called into question because of its supposedly bureaucratic, inefficient and oppressive character while the voices of capital are presented not as particular, vested interests concerned with maximising profits for their shareholders but as stewards of the economy, guardians of prosperity, and thus of the general interest.

The following table is a comparison of the amount of speaking or quotation time given to business and union leaders in the five week 2015 General Election campaign in the United Kingdom by five news programmes of the five terrestrial broadcasters. What is striking is the almost complete absence of speaking time given to union leaders who still represent some 6.5 million union members in the UK. Because the views of business leaders are objective, impartial, and essentially unpolitical they do not need to be balanced in the world of impartial broadcasting by competing opinions from civil society (Deacon et al, 2016). 


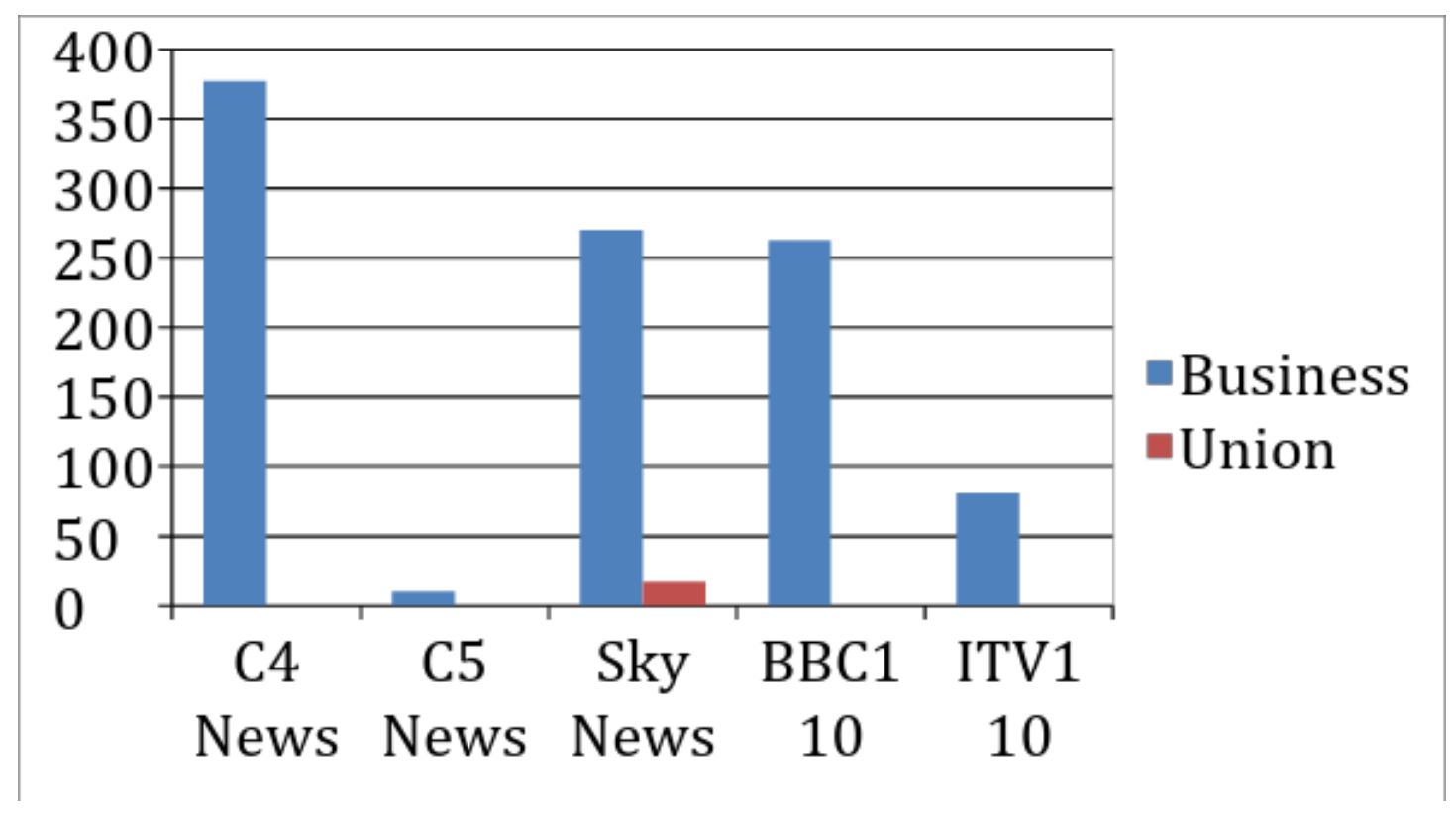

Source: Loughborough Communication Research Centre 2015

Given the broadcasters obligations to impartiality, what was going on here? If we analyse the broadcasts what we find is that what impartiality apparently means here for the broadcasters is that once business leaders have been interviewed representatives of different political parties are then asked to comment. Impartiality then means some sort of balance of speaking time between political parties whereas it does not apply to the opinions expressed by business leaders. In a sense the views of business provide the ground or 'the reality' over which politicians then argue.

On the second day of the 2015 General Election campaign The Daily Telegraph, the most right-wing of the UK’s quality newspapers, published a letter signed by 103 business leaders praising the Conservativeled government for having reduced corporation tax thereby signaling that Britain is 'open for business'. This has led, they argue, to Britain becoming the fastest growing advanced economy, higher investment and job creation. This is the neoliberal economic argument in a nutshell - lower taxation and a smaller state is good for everybody. This letter dominated the news agenda right at the beginning of the election as broadcasters followed The Daily Telegraph's lead. George Osborne, taking to the airwaves, described 
the carefully orchestrated letter 'as an unprecedented intervention in a UK General Election'. In contrast to Hall's historical conjuncture we can see an elected government attempting to derive legitimacy from a relatively small number of business leaders working in firms employing around 500,000 workers. What is striking about the impartial broadcast coverage of this letter is the absence of questioning of the claims of the business leaders apart from Labour Party politicians, whose interests in doing so can easily be discounted. Coverage of the letter was the first item on the BBC's News at 6 and News at 10, the two most watched BBC news programmes. Kamal Ahmed, the BBC's then Business Editor, was on tour with David Cameron and George Osborne to a West Midlands brewery where the Chief Executive Officer had been one of the signatories of The Daily Telegraph letter. At one point, Ahmed interviews George Osborne on board the Conservative election 'battle bus'. Ahmed briefly interviews the Chief Executive of the brewery after having explained that he is concerned about taxation levels:

Ahmed: "Do you worry about business people becoming involved in politics? Is it a good place for you to be?

CEO: “I’m not sure that I think taxation is necessarily becoming involved in politics than stating what I think is the obvious about what is good for our business. I know what is good for us to be able to make an investment. I know what is good for us to be able to employ more people.”

This is an interesting case of stake management where the CEO finding himself in a stake dilemma denies his stake because being 'political' is understood as being partial and as necessarily contentious and instead presents himself as being entitled to present an opinion because of his category i.e. a business person, an expert who knows what is in the interests of his business and by extension the broader economy and by implication his experience of having managed a brewery (Edwards and Potter, 1992). He represents himself not as the supporter of a particular party despite the fact that he has recently signed a letter supporting the Conservative Party but as an apolitical expert who knows what is good for his business (see Potter, 1996 on category entitlement). The presupposition of Ahmed's question is that 
business people should not be involved in politics as politics is essentially a matter of contending views and business people should be disinterested rather than adopting a particular stance. Of course, this implies that business itself is not political and can be separated from the political occupying a different realm. The interview ends there after the CEO's claims to know what is good for business, investment and jobs. There is no follow up question asking why levels of taxation are not political when taxation plans are central to party political discourse. There is no follow up question asking how the CEO knows what is good for investment and employment. There is no interview with a union official or a worker at the factory to ascertain their views or with an economist who might dispute the 'obvious' link between lower corporation tax and job creation or an environmentalist who might question the desirability of economic growth. The category entitlement of the business man to speak about what is good for the economy (apparently lower corporation tax, investment and job creation) is not questioned. The acceptance of the stake management of separation off of the economic from the political and acceptance of this businessman's claim to category entitlement by the journalist allows him to speak unchallenged over the economy until Labour Party sources are referred to later in the piece (but see above). This is one important instance in the process of the legitimation of neoliberalism, which consists of many similar instances that accumulate over time and help to explain why 'impartial' broadcasters do not feel the need to balance the voices of business people. Their unequal economic power, the absence of reciprocity between employer and employee, is legitimated through the accumulated acceptance of claims to know best and determine what is in the best interests of the population so that it becomes 'common sense' and is a crucial aspect of ideology production in this historical conjuncture. While the ideology of neoliberalism may appear at times to be unassailable, a second crucial feature of our historical conjuncture is that we are experiencing not a financial crisis but a crisis of neoliberalism as an economic theory and practice, which provide ample grounds for intellectual and political contention (Dumenil and Levy, 2011). 


\section{Conclusion}

In this response to our critics, we have sought to make the case for a reinvigorated concept of ideology disassociated from notions of deception and false consciousness. We have argued that what is required is an ethical foundation to ideology critique, which we believe the reflexive political philosophy of Rainer Forst points towards. Once we understand ideology as a type of pathology, and ideology critique as exposure of the ways in which unreciprocal or unequal power relationships are justified then we can also see power as a neutral rather than normative concept. There is nothing wrong with the exercise of power per se but rather the particular conditions under which it is exercised. The outcome of such conceptual renewal, we hope, is that we can engage in a more comprehensive and persuasive critique of the present neoliberal historical conjuncture than would otherwise be possible and this may connect to a political praxis grounded in the ethics of reciprocity and equality.

\section{References}

Allen, A., Forst, R., and Haugaard, M. (2014) 'Power and reason, justice and domination: a conversation' in Journal of Political Power 7(1) 7-33

Austin, J. L. (1962) How to do Things with Words, Oxford: Clarendon Press.

Collier, A. (1994) Critical Realism, London: Verso.

Corner, J. (2001) ‘Ideology: a note on conceptual salvage’ in Media, Culture and Society 23(4) 525-533

Corner, J. (2016) '’Ideology’ and Media Research’ in Media, Culture and Society 38(2) 265-273

Davidson, D. (1974) 'On the very idea of a conceptual scheme' in Proceedings and Addresses of the American Philosophical Association Vol 47 5-20

Dawes, S. (2016) 'Foucault-phobia and the problem with the critique of neoliberal ideology' in Media, Culture and Society 38(2) 284-293

Deacon, D., Downey, J., Stanyer, J. and Wring, D. (forthcoming) xxxxxx

Downey, J. (2008) 'Recognition and the renewal of ideology critique’ in Hesmondhalgh, D and Toynbee, J. eds The Media and Social Theory, Routledge: London 
Downey,J., Titley, G., and Toynbee, J. (2014) ‘Ideology Critique: the challenge for media studies’ in Media, Culture and Society 36(6) 878-887.

Dumenil, G. and Levy, D. (2011) The Crisis of Neoliberalism, Harvard University Press, Cambridge.

Edwards, D. and Potter, J. (1992) Discursive Psychology, Sage, London.

Forst, R. (2014) Justification and Critique: towards a critical theory of politics, Polity Press, Cambridge.

Gane, N. (2012) ‘The governmentalities of neoliberalism: panopticism, post-panopticism and beyond' in The Sociological Review 60(4) 611-634

Hall, S. (1982) 'Encoding and decoding in the television discourse', paper for the Council of Europe and Centre for Mass Communication Research

Hall, S. (1982) 'The rediscovery of 'ideology': the return of the repressed in media studies' McCartney, J (1976) 'The theory of ideology: some comments on Mepham’ in Radical Philosophy 13 2831

Phelan. S. (2016) 'Reinvigorating ideology critique: between trust and suspicion’ in Media, Culture and Society 38(2) 274-283

Potter, J. (1996) Representing Reality: Discourse, Rhetoric and Social Construction, Sage: London. 